\title{
HVMANITAS
}

\section{Emmanuil Roídis: un clásico griego del siglo XIX}

\section{Autor(es): $\quad$ Vilela, Carmen}

Publicado por: Imprensa da Universidade de Coimbra

URL

persistente:

URl:http://hdl.handle.net/10316.2/27388

DOI:

DOI:http://dx.doi.org/10.14195/2183-1718_64_13

Accessed : $\quad$ 26-Apr-2023 12:40:16

A navegação consulta e descarregamento dos títulos inseridos nas Bibliotecas Digitais UC Digitalis, UC Pombalina e UC Impactum, pressupõem a aceitação plena e sem reservas dos Termos e Condições de Uso destas Bibliotecas Digitais, disponíveis em https://digitalis.uc.pt/pt-pt/termos.

Conforme exposto nos referidos Termos e Condições de Uso, o descarregamento de títulos de acesso restrito requer uma licença válida de autorização devendo o utilizador aceder ao(s) documento(s) a partir de um endereço de IP da instituição detentora da supramencionada licença.

Ao utilizador é apenas permitido o descarregamento para uso pessoal, pelo que o emprego do(s) título(s) descarregado(s) para outro fim, designadamente comercial, carece de autorização do respetivo autor ou editor da obra.

Na medida em que todas as obras da UC Digitalis se encontram protegidas pelo Código do Direito de Autor e Direitos Conexos e demais legislação aplicável, toda a cópia, parcial ou total, deste documento, nos casos em que é legalmente admitida, deverá conter ou fazer-se acompanhar por este aviso.

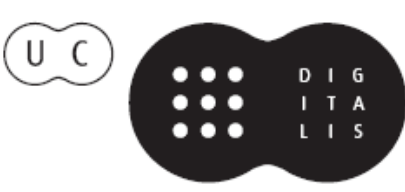


humanitas

\section{Vol. LXIV \\ 2012}

IMPRENSA DA UNIVERSIDADE DE COIMBRA

COIMBRA UNIVERSITY PRESS 


\section{EMMANUIL ROÍDIS. UN CLÁSICO GRIEGO DEL SIGLO XIX}

\section{Carmen Vilela}

\section{Resumen}

En el presente artículo se analiza la figura literaria de Emmanuil Roídis, uno de los grandes escritores del siglo XIX, y se resalta la influencia que en él ejercen los clásicos grecolatinos, comentando sus obras traducidas al español.

Palabras clave: figura literaria de Emmanuil Roídis, influencia de los clásicos grecolatinos, obras traducidas al español.

\footnotetext{
Abstract

This article considers Emmanuil Roídis as a literary figure and one of the great writers of the Nineteenth Century, as well as the influence on his work of the Greek and Latin classics.

Keywords: Emmanuil Roídis as a literary figure, classical influence on his work, translations in Spanish.

\section{1.- Semblanza de Emmanuil Roídis. Su papel en las letras neohelénicas.}

Emmanuil Roídis es una de las grandes figuras literarias del siglo XIX griego. Su importancia literaria se cifra en tres aspectos, inseparables entre sí: a) Su faceta como literato, esto es, su enorme contribución a la formación de la prosa griega moderna, inventando nuevas técnicas de narración. b) $\mathrm{Su}$ faceta como crítico. Es decir, la presencia pública activa de un discurso crítico que combina el interés teórico, la agudeza de la argumentación y la
} 
innovación en el estilo. c) Su valía como ensayista, que aúna el radicalismo crítico con la maestría narrativa.

Nació en 1836, en Hermúpolis (isla de Siros, Cícladas), en el seno de una familia acomodada y culta. Desde niño vivió en diferentes países de Europa (Italia, Rumanía, Alemania, Francia...), en los que realizó estudios e investigaciones. En 1862 fijó su residencia definitivamente en Atenas, donde murió, en 1904. Fruto de su larga estancia en la capital son sus irónicos escritos titulados Paseos por Atenas, llenos de anécdotas y recuerdos de la vida cotidiana de la ciudad.

Muy pronto comienza a escribir artículos políticos en el periódico griego antimonárquico Amanecer. En 1866 publica La papisa Juana, un estudio sobre la Edad Media. A partir de 1870 colabora en periódicos extranjeros y en medios literarios y periodísticos griegos, con ensayos sobre literatura, lengua o política en los que, bajo diferentes pseudónimos la mayoría de las veces, critica a políticos y comerciantes griegos o se implica en disputas literarias.

Si hemos de dar el perfil humano del personaje, cabe definirlo como un dandi, un joven mundano con una intensa vida social y proclive al lujo. Era rico, agresivo, inteligente, donjuán y excelente escritor. Poseía gran inteligencia y una insaciable ansia de saber. Leía toda clase de libros, lo que le proporcionó amplísimos conocimientos generales y especializados en todas las ramas del saber. Su obra, propia de un enciclopedista, abarca estudios, filosóficos, filológicos, históricos, sobre todo los relacionados con la Edad Media, época por la que se sentía profundamente atraído. Es el típico griego europeizado del siglo XIX, libre de los prejuicios de su época, amante del progreso, al tiempo que conservador, imbuido de lecturas extranjeras.

Roídis es una de las mentes más lúcidas de la historia de la nueva Grecia. Sus enemigos lo llamaron con desprecio Voltaire y Luciano (en alusión al sofista de Samosata). Ciertamente no iban descaminados. Era un librepensador, un inconformista con una actitud crítica y provocadora, situado en permanente estado de refutación y duda, para quien la palabra 'escribir' significa 'oponerse' porque concibe al intelectual como un objetor irreductible.

Le tocó vivir momentos históricos difíciles. El recién creado Estado griego tenía que afrontar su propia organización interna, tanto política como administrativamente. En una democracia parlamentaria incipiente, los partidos políticos eran agrupaciones sin ideología determinada cuya única 
meta era acceder al poder, para lo cual debían satisfacer las ambiciones de su clientela de votantes. No son pocas las alusiones de Roídis a la corrupción de los partidos políticos y a las tumultuosas sesiones en la Cámara.

De otra parte, la política exterior de Grecia estaba dominada por la Megali Idea (Gran Idea), la pretensión de restaurar el Imperio bizantino incorporando al nuevo Estado griego toda la Península balcánica y el Mediterráneo oriental, con capital en Constantinopla. A esto se sumaban los problemas relacionados con la propia Iglesia griega, que en 1833 se declara independiente del patriarcado de Constantinopla, quedando sometida a un grado considerable de control gubernamental y dominada por fuerzas retrógradas, civiles o clericales, que la impelían a perseguir a quienes no pensaban como ellos.

Frente a esta situación, Roídis toma una actitud beligerante. Se enfrentó a los poderes políticos y espirituales de su tiempo, y su enfrentamiento revistió habitualmente la forma de escándalo en todas las facetas de su producción literaria. Su lenguaje irónico fue el vehículo con el que dio salida a su fuerte actitud crítica en todos los terrenos: En el terreno social y religioso, con su obra La papisa Juana (1866), de la que hablaremos más adelante. En el de la política, con su faceta periodística, donde da impulso a la más acerada sátira en el discurso público. En el campo de la crítica literaria, con sus demoledoras opiniones sobre la situación de la poesía neohelénica. En el terreno lingüístico, con sus posiciones en defensa de la lengua demótica ${ }^{1}$.

1 La llamada "Cuestión lingüística" de la Grecia moderna, la disputa entre los partidarios de la cazarévusa y los que defendían la demótica, es heredera de una larga tradición. Del siglo XVIII proceden los dos términos para definir los dos tipos de lengua: cazarévusa o lengua purista y demotikí o demótica, lengua popular. La primera recreaba en la medida de lo posible la lengua actual pero tendiendo a su modelo clásico (ático) en fonética, morfología y léxico e imitando la sintaxis de las lenguas foráneas (francés y alemán sobre todo). A finales del siglo XIX surge una tendencia renovadora capitaneada por la llamada Nueva Escuela Ateniense, o Generación de 1880 que reacciona contra el culto excesivo a la Antigüedad, censura el lenguaje pomposo y retórico, el pseudoheroísmo del Romanticismo, y busca simplicidad en la expresión, repudiando el uso de la lengua cazarévusa. Figura destacada de este movimiento es Yanis Psijaris, quien en su famoso Manifiesto asume públicamente la defensa de la lengua demótica e insta a los creadores literarios a prescindir de la cazarévusa y lanzarse al uso literario de la lengua que habla la gente común. Los partidarios de la lengua demótica, con su actitud combativa la dotaron de sólidas bases teórico-lingüísticas y de una poderosa justificación ideológica. 
Su postura ante la diglosia lo lleva a escribir numerosos trabajos y ensayos $^{2}$, en los que propugna ennoblecer y desarrollar literariamente la lengua viva del pueblo. Pese a apoyar el Manifiesto de Psijaris, Roídis aconseja no desterrar de un plumazo la cazarévusa, la lengua en la que su generación se siente cómoda porque es la que conoce. A este respecto dice con un cinismo digno de Luciano: "Respeto a los muertos, incluso cuando aún están vivos".

\section{2.- La obra literaria de Roídis traducida al español ${ }^{3}$.}

\section{La papisa Juana. Un estudio sobre la Edad Media.}

Su obra de más éxito fue La papisa Juana. Un estudio sobre la Edad Media. Su publicación provocó un gran escándalo y fue un revulsivo para la época. La sociedad se convulsionó. Toda Grecia se desternilló de risa con su lectura; muchos admiraron a Roídis, alabando su estilo magistral, su jovialidad, su malicia. En la prensa proliferaron los artículos a favor o en contra de esta novela y de su autor. Durante todo el siglo XIX la novela se editó muchas veces en griego, adquirió fama legendaria y se tradujo a muchas lenguas, con una difusión inaudita para una obra griega. A esto contribuyó la trama -un escándalo eclesiástico en la Edad Media- la certera construcción de la obra, la gracia y el sarcasmo que despliega y la tempestad que estalló con la excomunión del libro por la Iglesia ortodoxa.

En efecto, el demoledor ataque a la Iglesia ortodoxa, columna vertebral de la nueva Nación, la acerada sátira anticlerical y la mofa de la superstición religiosa concitaron en su contra todos los odios del clero y provocaron una fuerte reacción del Sínodo, que repudió públicamente esta novela y la excomulgó, como anticristiana y dañina por sus irreverencias, maledicencias y obscenidades y por las sátiras y parodias contra la Religión, los Sagrados Misterios y la Iglesia, recomendando a los fieles que se abstuvieran de leer este libro "nocivo para el alma y para el cuerpo". Y no le bastó al Sínodo

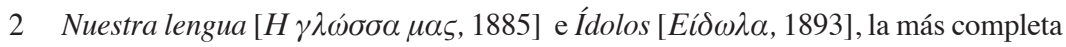
y sistemática, después de La papisa Juana.

3 La papisa Juana. Un estudio sobre la Edad Media (2006). Universidad de Sevilla. Paseos por Atenas. Ensayos y estudios históricos. (2008). Universidad de Sevilla. Relatos de Siros. Recuerdos y reflexiones (2010). Universidad de Sevilla. 
con excomulgar la obra; trató de que fuera condenada en juicio público y civil por los poderes del Estado.

\section{Paseos por Atenas. Ensayos y estudios históricos.}

Pese al éxito de La papisa Juana, Roídis fue por encima de todo un extraordinario ensayista. La fuerza de su pensamiento se muestra en mayor plenitud en la diatriba y la argumentación teórica.

La selección de artículos que hemos titulado Paseos por Atenas. Ensayos y estudios históricos recoge una buena parte de su obra ensayística, que abarca una amplia gama de contenidos. Esta selección es como un collage en el que se nos ofrece una visión crítica de la situación política, sociológica, cultural y científica del recién creado Estado neohelénico, y en el que lector amante de Grecia, la antigua y la moderna, encontrará muchas claves para interpretar y entender aquella ciudad y aquel país.

\section{Relatos de Siros. Recuerdos y reflexiones.}

Además de un ensayista magistral, Roídis es un excelente escritor de relatos. Relatos de Siros. Recuerdos y reflexiones recoge su narrativa breve. Se trata de originales, inteligentes y sarcásticas historias de carácter biográfico referidas a su primera juventud en su patria chica, o de recuerdos y sucesos llenos de humor, vividos en sus viajes al extranjero. Cada uno de ellos, contemplado individualmente se puede percibir como un detalle de la enorme pintura mural que representa el estilo y la actitud ética del autor.

En 1890, treinta años después de la publicación de La Papisa, empezaron a aparecer en la prensa escrita los llamados Relatos de Siros. En el siglo XIX Siros era un floreciente centro económico, cultural y comercial y su capital, Hermúpolis, gozaba de un ambiente social burgués y urbano -realmente la primera sociedad urbana que tuvo Grecia-. Pues bien, esta burguesía local, un tanto pueblerina y gazmoña, tampoco se salva del aguijón satírico de su egregio convecino. Los Relatos están considerados su mejor trabajo desde el punto de vista literario y son bastante representativos de su última época como escritor.

\section{3.- Roídis y los clásicos}

Es un hecho que la aportación de Roídis a las letras griegas lo convierte en un clásico de la literatura neohelénica. Pero es innegable también lo 
mucho que él debe a los clásicos antiguos. Su sólida formación humanística queda constatada en toda su obra. De una parte, en citas directas de clásicos griegos y latinos, desde los trágicos a los filósofos, así como en alusiones constantes a personajes de la mitología, de la historia o del mundo antiguo, en general. De otra, en su particular estilo y en el uso de claves literarias griegas, elementos que forman parte de su obra de un modo tan sutil e interiorizado, que haría falta un estudio concreto de este aspecto.

Aunque toda la obras de Roídis, ensayos, relatos, monografías, etc., rezuma sabor a los clásicos, por razones de espacio y tiempo, centraremos nuestro análisis fundamentalmente en su única novela, La papisa Juana.

\section{1.-Reminiscencias clásicas en el estilo.}

Desde el punto de vista del estilo, La papisa Juana tiene la resonancia de las obras de la Antigüedad. Como la tragedia griega, el autor se sirve del mito para decir lo que no podría haber dicho de otra forma. En un momento en que la novela histórica, el único tipo de novela cultivado entonces, fortalecía el mito del nuevo helenismo, Roídis, desplazándose a un ambiente ajeno al público griego, ridiculiza los tonos románticos y el planteamiento lingüístico ultra arcaizante de la Vieja Escuela de Atenas. Y más aún, con el espíritu enciclopedista y volteriano que lo caracteriza, aprovecha también esta escandalosa figura de un papa hembra para arremeter, no contra el Papa y la Iglesia católica, sino contra la Ortodoxia, piedra angular sobre la que se pretendía sustentar la identidad y la construcción del naciente Estado griego y su peregrina intención de recomponer las fronteras del pasado ${ }^{4}$.

La Papisa es pura exuberancia simbólica. Lo que el autor define como "Estudio sobre la Edad Media" es una despiadada sátira contra su propio tiempo, con alusiones constantes a sus contemporáneos, ya sean políticos, escritores o simples ciudadanos, contra la superstición religiosa y los falsos predicadores. Roídis censura la pomposidad, el retoricismo, el pseudoheroísmo, la novela romántica y la superchería religiosa, y lo hace utilizando de forma magistral la parodia y el retruécano, la descripción de situaciones cómicas y absurdas. En esto es heredero de Aristófanes y de la comedia antigua. Veamos algunos ejemplos.

4 Marco Hierro, E. (2002): Erytheia 23. 307-330. 


\subsection{1.-Parodia de autores clásicos.}

A veces parodia un único verso de un poeta antiguo. En la página $77^{5}$

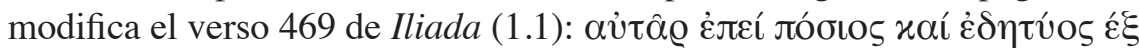
Égov évтo (después que hubieron satisfecho el deseo de comer y beber),

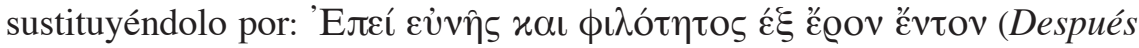
que hubieron satisfecho el deseo de cama y sexo).

El propio Roídis, en nota a pie de página, nos advierte de que la expresión de la página 79: Tales dorados días pasaban los progenitores de Juana gozando de sus tiernos miembros, es un calco de Teócrito, Idilio 27.65.

Tampoco Eurípides escapa a la zarpa satírica de nuestro autor. En la

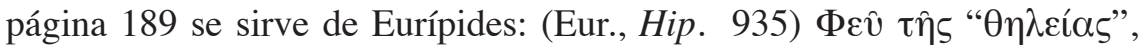

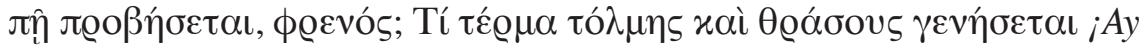
del corazón de la mujer! ¿Hasta dónde es capaz de llegar? ¿Dónde estará el límite de su osadía y de su locura? (Trad. C. Vilela).

No falta tampoco la parodia de escenas completas. Veamos la descripción del ambiente festivo de los monjes del monasterio de Fulda en la noche de san Juan, magistral reproducción cómica de textos de Tibulo, Ovidio y Propercio:

Cada año se encendían por doquier innumerables hogueras en honor del santo, alrededor de las cuales se divertían y danzaban los fieles como sus antepasados alrededor de las hogueras de las Parelias... La fiesta estaba en todo su apogeo cuando los dos viajeros entraron en el patio del monasterio. Unos monjes arrojaban al fuego gavillas de paja y barriles vacíos. Otros, con el hábito arremangado, saltaban sobre las sagradas llamas tirándose luego a una alberca llena de agua cada vez que el fuego mordía sus desnudas piernas... o tumbados en la hierba, metían los tenedores en las marmitas y los vasos en las tinajas de vino (La pap. 2.124).

(Tib. Eleg.2.5):

Ille levis stipulae solemnis potus acervos. Accendet flammas transilietque sacras.

5 Todas las alusiones a páginas remiten a nuestra traducción La papisa Juana. Un estudio sobre la Edad Media (2006). 
El (pastor) bebido, prenderá fuego a los rituales montones de ligera paja y saltará las hogueras sagradas. (Trad. A. Soler).

(Ovid. Fast. 4.782):

Moxque per ardentes stipulae crepitantis acervos

Traiicias celeri strenua membra pede.

Y luego procede que atravieses con cuerpo diligente y con pie ligero los montones ardiendo de leña crepitante. (Trad. B. Segura).

(Prop., Eleg. 4.4):

Annua pastorum convivia, lusus in urbe, Quum pagana madent fercula deliciis

Quumque super raros foeni flammantis acervos

Traiicit immundos ebria turba pedes...

Se celebraba el banquete anual de los pastores, juegos en Roma, fecha en la que las bandejas de los campesinos rebosan abundancia y en la que la muchedumbre, embriagada, salta con sus sucios pies sobre espaciadas gavillas de heno en llamas. (Trad. A. Ramírez de Verger).

Igualmente, en el divertido episodio de la visita a la tumba de la Magdalena se reconocen los versos del Canto 3 de la Eneida:

Agachando sus grandes orejas como hacen todos los jumentos cuando se disponen a cometer una estupidez, zarandeó con los dientes tan violentamente aquel arbustillo milagroso, que lo arrancó de cuajo y se quedó con él en la boca... Los amantes se estremecieron de horror... al ver la abundante sangre que goteaba de la raíz del arbusto. Del hoyo abierto salían fuertes lamentos... En medio de todo esto se oyó una doliente voz de mujer que maldecía a aquella glotona criatura (La pap. 3.153).

(Virg., En. 3.26-28):

Horrendum et dictu video mirabile monstrum.

Nam, quum prima solo raptis radicidus arbos

Vellitur, huic atro liquuntur sanguine gutae...

Presencio un horrendo prodigio inenarrable. Del arbusto que logró primero descuajar cortando sus raíces, van fluyendo gotas de sangre negra que oscurecen con sus cuajos la tierra. (Trad. J. Echave-Sustaeta). 
(Virg., En. 3.39-40):

... Gemitus lacrymabilisimo.

Auditur tumulo et vox reddita fertur ad aures.

Desde lo hondo del cerro se percibe un gemido lastimero y me llega esta voz a los oídos. (Trad. J. Echave-Sustaeta).

Malévola sorna destilan sus comentarios sobre el estado de ánimo de Frumencio:

Juana al principio trataba de tranquilizar a su compañero... Pero Frumencio era difícil de convencer y las mujeres se cansan pronto de la melancolía. Incluso las Oceánides, a pesar de ser diosas, sólo un día se quedaron consolando a Prometeo encadenado; luego, aburridas de sus quejas lo dejaron en la roca con el buitre que le roía las entrañas (La pap. 3.179).

La escena del abandono de Frumencio por Juana emula, en clave de humor, el de Ariadna por Teseo, según los conocidos versos de Ovidio en la Carta de Ariadna a Teseo, recogida en Heroidas.

Cuando al día siguiente antes de amanecer abrió los brazos para rodear a su amada, sólo pudo abrazar la paja del jergón. Se estremeció de horror, tendió los brazos y palpó en la oscuridad, como Polifemo, ciego, buscando a Odiseo... Corrió hacia la playa como un jabalí, saltando de peña en peña, llamándola con desgarrados gritos ¡Juana! Las huecas rocas repetían sus gritos y cuantas veces él la llamaba, tantas gritaban ellas a la que se había ido, como si se compadecieran del aquel desgraciado. Y hasta el mismo sol salió en aquel preciso instante para prestarle ayuda en su angustiosa búsqueda (La pap. 3.185).

(Ovid., Heroi.10.8-11):

Incertum vigilans, a somno languida, movi

Thesea prensura semisupina manus;

Nullus erat! Referoque manus iterumque retempto,

Perque torum moveo braccia: nullus erat!

Sin acabar de espabilarme, atontada de sueño, moví las manos, medio dormida, para abrazarme a Teseo: no estaba; vuelvo a echar los brazos y busco otra vez, pasando las manos por toda la cama: no estaba. (Trad. A. Pérez Vega). 
(Ovid. Heroi. 10.22-25):

Reddebant nomen concava saxa tuum

Et quoties ego te, toties locus ipse vocabat,

Ipse locus misere fere volebat opem.

Las cóncavas rocas me devolvían tu nombre, y cuantas veces yo te llamaba, otras tantas te llamaba aquel paraje. Hasta el propio paraje quería ayudar a esta pobre. (Trad. A. Pérez Vega).

No sólo Ovidio le sirve de jocosa inspiración en este pasaje. También el epilio de Catulo titulado Bodas de Tetis y Peleo.

Pero ninguna de las santas que allí habitan bajó para ofrecerle el consuelo de sus labios, como Baco a Ariadna (La pap. 3.186).

(Cat., Bodas de Tetis y Peleo, 252-254):

At parte ex alia florens volitabat Iaccus,...

Te quaerens, Ariadna, tuoque incensus amore.

Pero en otro recuadro de la colcha, Yaco, en la flor de su juventud... corría veloz buscándote, Ariadna, y enardecido por tu amor. (Trad. A. Soler).

\subsection{2.- Otros recursos estilísticos de sabor clásico.}

Ya hemos dicho que por su cinismo, su actitud provocadora, su rebeldía, su falta de respeto hacia todo lo divino y lo humano, se le comparó en su época con Luciano de Samosata. No sólo en su actitud vital recuerda Roídis al escritor de la Segunda Sofística, también en sus recursos estilísticos. A veces, la lectura de La papisa Juana produce la sensación de que el propio narrador ha hecho de sí mismo un personaje de la obra, recurso típico de la novela antigua, que Luciano y Apuleyo utilizan. Por si esto no fuera suficiente, Roídis arrebata a Luciano el título de un ensayo, "Viaje a la Luna", en el que nos ofrecen un dechado de sofismas llenos de gracia e ingenio. Y lo mismo podemos apreciar en los titulados "Orestes y Pílades", "Criseidas" o "Días nefastos"6, dos de ellos dedicados a personajes del mito.

6 Todos ellos recogidos en la recopilación que hemos titulado Relatos de Siros. Recuerdos y reflexiones. 2010. 
Ejemplos de perfectas construcciones sofísticas, tanto en la forma como en el fondo, son también sus $\Sigma \varkappa \alpha \lambda \alpha \theta \dot{\varrho} \mu \alpha \tau \alpha$, Fruslerías $^{7}$. Se trata de brevísimos relatos que tienen como fondo un juego dialéctico sustentado en un sofisma oculto que se desarrolla a base de acrobacias mentales, tanto más logradas cuánto más elaboración se requiere para encubrir el sofisma. Por ejemplo, en uno de ellos se sostiene con argumentos aparentemente irrebatibles a la par que divertidos, que la holganza es el mayor de los bienes, y que así lo estiman la mayoría de los hombres, dado que trabajan para sentir el placer de la ociosidad. En otro, con una lógica aplastante, se razona que los animales son superiores y más perfectos que el hombre, basando esta burda afirmación en el hecho de que cuando un hombre destaca por encima de la media debido a sus defectos o virtudes, automáticamente deja de ser comparado con otro hombre y empieza a ser comparado con un animal: "fuerte como un león", "astuto como una serpiente", etc. Las técnicas de razonamiento que utiliza nos retrotraen a la Segunda Sofística y al mismísimo Gorgias.

Las reminiscencias clásicas de su estilo se pueden constatar también en sus recursos literarios para no aburrir al lector, su particular

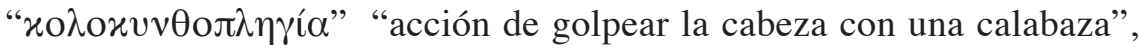
lo que, en sentido metafórico, confiesa haber copiado de Séneca. Consiste en abusar de dichos chocantes que se repiten una y otra vez, frases hechas a modo casi de fórmulas homéricas, símiles, comparaciones, hipérboles, retruécanos, descripciones, digresiones, etc., para zamarrear al soñoliento lector.

\subsubsection{Uso directo de fuentes grecolatinas.}

La erudición del autor de La papisa y su conocimiento de la Antigüedad y de la Edad Media se aprecian igualmente en la proliferación de citas de autores antiguos, a quienes apela como autoridad:

Herodoto consideró conveniente exponer al comienzo de su Historia los motivos que lo habían movido a contar los triunfos de Milcíades y los 'trágicos' amores de las mujeres de Egipto. Los historiadores posteriores, Tucídides, Tácito, san Lucas, Gibbon y Guizot se dispusieron a imitar el

7 Remitimos a la recopilación de ensayos que hemos titulado Paseos por Atenas. Ensayos y estudios históricos. 2008. 
buen ejemplo del Padre de la Historia. Así, todas las historias comienzan de forma convencional por la justificación del historiador, como los poemas épicos comienzan por la invocación a las Musas. Obedeciendo yo a esta regla de la Historia, expondré... (La Pap. Prefacio, 25).

En este sentido, leemos en La papisa 1.89: Ignoro si Juana había leído a Luciano, pero cuando cerró los ojos también tuvo un sueño, como el de Samosata. Alusión directa a la obra de Luciano, El sueño, en la que cuenta que siendo adolescente se le aparecieron en sueños dos figuras femeninas ofreciéndole cada una un camino profesional.

Referencias a Plutarco, a la Poética de Aristóteles y al propio Horacio, aparecen por doquier para apoyar sus ataques contra los abusos literarios de algunos escritores de su época. Otras veces necesita apelar a la autoridad de los antiguos para cubrirse las espaldas cuando señala la pervivencia de costumbres y dioses paganos en las del Medievo, o hace afirmaciones que pueden parecer escandalosas a sus contemporáneos o al muy cristiano clero ortodoxo, que condenó su obra. Su Apéndice de notas incluido al final de La papisa es ilustrativo al respecto.

Destaquemos algunas de ellas, sin ánimo de ser exhaustivos. Posidonio, Estrabón y el propio Gregorio de Tours le sirven de base cuando dice:

Este ídolo había sido sumergido en el fondo del lago por san Bonifacio con un soplo, pero sus antiguos adoradores aunque ya estaban cristianizados conservaban en las entretelas de su corazón ciertos residuos de devoción a su ahogado protector, al que seguían ofreciendo presentes, y una vez al año arrojaban al agua dulces, velas, pasteles de manzana y quesos ( $\mathrm{La}$ pap. 1.119).

El mismo Roídis nos ofrece sendos textos de Estrabón y de Gregorio de Tours que corroboran sus palabras:

(Estr. Edit. Didot, 156):

Estos depositaban en los lagos pesos de oro y plata. Así pues, los romanos al conquistar estas tierras declararon los lagos propiedades del Estado y muchos que habían comprado molinos encontraron objetos de plata cincelados. (Trad. C. Vilela). 
(Greg. de Tours Glor. Confes. 2):

En la tierra de los gavaleos (hoy Gevaudan) en la cima de un monte llamado Elano había un lago al que, en determinada época del año, los lugareños arrojaban como ofrendas lienzos blancos, pieles de cordero, quesos, pescados salados y otras muchas dádivas. La mayoría iban allí en carros, en los que transportaban vino y animales que sacrificaban. La fiesta duraba tres días y al cuarto día las aguas del lago se agitaban, el sol se ocultaba y estallaba una tormenta de granizo y relámpagos, tan fuerte que los peregrinos no tenían tiempo de ponerse a salvo. Todo esto sucedía invariablemente cada año el mismo día y a la misma hora. (Trad. del griego moderno, C. Vilela).

A propósito del episodio de las hogueras de la noche de san Juan (La pap. 2.124) Roídis apostilla: "También las hogueras de san Juan son herencia del paganismo, como la mayoría de los rituales populares del Cristianismo. Los romanos durante los días más largos del año encendian hogueras en honor de Pales, dios de los rebaños". Y nos remite a Dionisio de Halicarnaso, Antigüedades romanas 1.8, a los ya comentados Tibulo y Propercio y a la obra de Alfred Maury, Historia de la magia, página 164.

Y justifica el comentario: "Príapo era adorado aún en Germania bajo el nombre de san Vito" (La pap. 2.132) con la siguiente nota:

La mayoría de nuestros santos son en realidad dioses o héroes griegos que han cambiado su nombre, pero en todo lo demás son idénticos a los antiguos. San Nicolás sustituyó a Poseidón, que levanta o calma las tempestades. San Miguel conduce al Paraíso o al Infierno (Hades) a las almas, como antes hacía Hermes. San Demetrio es el dios Pan de los pastores cristianos. Helios es adorado aun hoy día en las cumbres de los montes con el nombre de san Elías, etc. (La pap. 257. Apéndice de Notas).

Nuestro erudito autor detecta en los Fastos de Ovidio, la costumbre a la que alude en la página 165 de La papisa: "Ofreció un trozo de pan al icono de la Virgen..."

(Ovid. Fast., 5):

Mos erat et mensa credere adesse deos. Fert missos Vestae pura patella (plato) cibos.

Se creía que los dioses estaban presentes en los banquetes y que a Vesta se ofrecía siempre la primera ración. (Trad. A. Pérez Vega). 
Y añade que esta práctica se mantuvo entre los monjes del Monte Atos hasta el siglo XIX, como nos relata el inglés Covel:

(Covel, Viaje a Grecia 5.1): Cuando los monjes se sentaban a la mesa, el higúmeno cortaba una porción de pan que ofrecía en una bandeja de plata a la imagen de la Virgen, colocada cerca de la mesa. (Trad. del griego moderno, C. Vilela).

Según Roídis, los emperadores bizantinos pusieron gran celo cristiano en erradicar las prácticas paganas de todos aquellos desgraciados sospechosos de mantener la religión de sus padres.

El que sacrificaba un cordero con motivo de un banquete familiar, el que ponía flores en la tumba de su padre, el que recogía camomila a la luz de la luna, el que quemaba hierbas aromáticas en su dormitorio o llevaba colgado de forma visible un amuleto contra la fiebre, inmediatamente era denunciado como mago o idólatra por los espías encapuchados, lo encadenaban con pesados grilletes y lo enviaban a Escitópolis, donde se había instalado el `matadero' cristiano (La pap., 3.172).

Una afirmación tan peligrosa ha de estar bien justificada, por eso nuestro irreverente novelista, como testimonio escrito de sus afirmaciones, presenta íntegros dos pasajes muy poco conocidos de Libanio y Amiano Marcelino:

(Lib., Discurso, Ed. Reiske, 167-168.): En efecto, (los monjes) recorren los campos arrasando como torrenteras las tierras de cultivo... unos afirman que luchan contra los santuarios paganos, pero lo que pretenden es obtener lo que hay dentro de los templos, robando a los desgraciados sus bienes, los productos de la tierra (es decir, lo que tienen almacenado) y los animales que crían. Pero esto no les basta; también se apropian de la tierra de cualquiera, diciendo que es un santuario, y muchos son privados de sus ancestros por causa de un nombre, aunque no es cierto: otros se nutren de los males de demás, los que según dicen, sirven a Dios por medio del ayuno. Y si se enteran de que hay un campo que pueden apropiarse, entonces su dueño es acusado de sacrificar a los dioses y practicar la magia negra por lo que es preciso ir contra él y se presentan los represores, pues este nombre tienen los salteadores. Algunos intentan pasar desapercibidos y niegan cometer tales desmanes y si los llamas salteadores, se ofenden, pero otros se jactan de ello y se lo enseñan a los que no lo saben.... ( Trad. del griego moderno, C. Vilela). 
Y nos dice Roídis, minutos antes de ofrecernos el texto de Libanio: "Libanio en su discurso "En defensa de las cosas sagradas", el canto del cisne del helenismo que se muere, nos conmueve hasta las lágrimas relatándonos los sufrimientos de pobres lugareños, despojados por completo por los monjes" (La Pap. 263. Apéndice de Notas). Para continuar luego: "No menos grave es el testimonio de Amiano Marcelino que traducimos fielmente":

(Am. Marcel. 19.121.): Bastaba que uno fuera acusado por un espía malintencionado de que llevaba al cuello un amuleto contra la fiebre o que había sido visto sentado cerca de una tumba o de unas ruinas, para que fuera condenado a muerte como idólatra o practicante de la nigromancia. De los más apartados confines del imperio eran conducidos con cadenas ciudadanos de cualquier clase social o edad. De ellos, unos morían en el camino y otros en las cárceles. Los que sobrevivían eran llevados a Escitópolis, ciudad apartada, en Palestina, donde se habían instalado los lugares de tortura y de matanza. El primer torturado fue Simplicio, después de él, Parrasio, luego Andronisco. (Trad. del griego moderno, C. Vilela).

A propósito de la escabrosa afirmación "llegó un día en que... mientras el hambre despedazaba sus entrañas, como el buitre a Prometeo, estuvieron a punto de justificar la opinión del sabio Crisipo, que, entre otras cosas enseñaba a sus discípulos que era legítima la necrofagia", (La pap. 3.141), el propio autor nos remite a su fuente: Diógenes Laercio, 7.7, que habla de la opinión de Crisipo sobre la necrofagia, citando el Libro 3 de su obra Sobre el derecho, en la que sostiene que es legítimo comerse a los muertos.

Sutil es el calificativo de "neoplatónicos" que se da a los rijosos monjes que visitan a Juana en el eremitorio cercano al monasterio de Dafní, a las afueras de Atenas:

Juana, pensando que su hábito masculino era una coraza segura contra los concupiscentes deseos, o no conociendo aún las costumbres de aquellos neoplatónicos (La Pap. 3.178).

El término neoplatónico fue acuñado por los eruditos en el siglo XIX para separar a Platón de Plotino, revisor de las teorías del maestro. Roídis con sutilísima ironía está diciendo veladamente que aquellos monjes, paisanos de Platón, no sentían por Juana un amor "platónico” puro, sino 
un "amor platónico revisado", es decir, un amor más físico que espiritual, a pesar de ser, o precisamente por ser varón.

En La papisa 3.155: "en aquella época aún se ponía en duda que las mujeres formaran parte del género humano. Quienes negaban su pertenencia a la humanidad argüían sus 'trágicos' amores en Egipto y sus 'hípicos' amores en Tesalia" (Papisa, 3.155), hay una velada alusión a la noticia de Plinio (Nat. 8.64) sobre las uniones de las mujeres de Egipto con carneros y de las de las tesalias con caballos, y sobre los monstruos nacidos de estos amores, práctica recogida también en Herodoto (Euterpe, 49) y Filostrato (Vida de Apolonio de Tiana).

Hemos presentado una mínima muestra de la erudición clásica de nuestro autor, extraida exclusivamente de La papisa Juana. Las limitaciones de espacio impuestas por un artículo de esta naturaleza nos obligan a prescindir de ejemplos obtenidos de sus otras obras, plagadas igualmente de referencias, citas y requiebros al Mundo Antiguo.

\section{Bibliografía}

\section{Ediciones griegas de la Papisa Juana, de E. Roídis}

Anguelu, A 'A $\pi \alpha \nu \tau \alpha$, vol. I, Atenas, 1978.

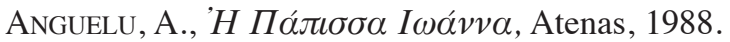

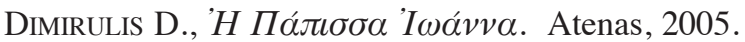

\section{Estudios monográficos sobre E. Roídis}

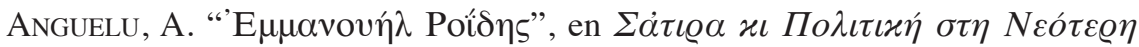

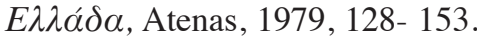

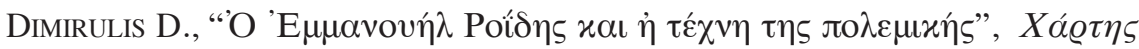
15 (1985), 266-290.

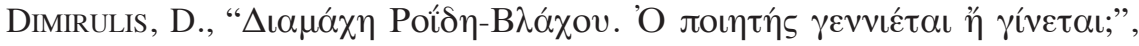

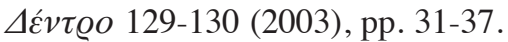

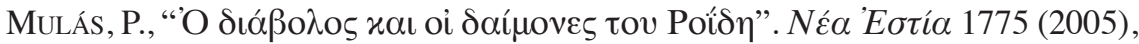
pp. 219-224.

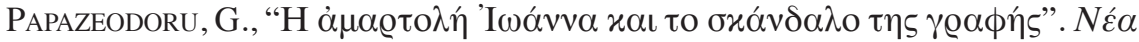

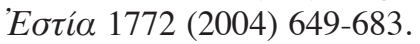

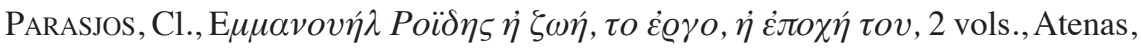
1941-1950. 


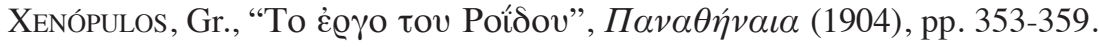

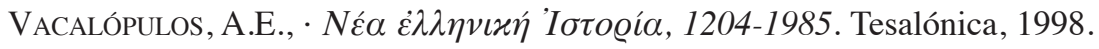

\section{Estudios sobre La papisa Juana}

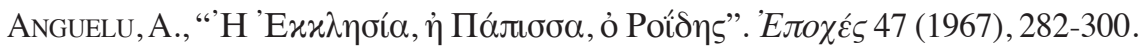
(También en su edición a la Пá

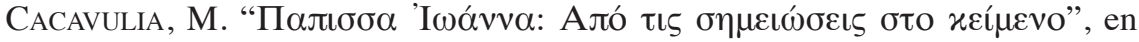

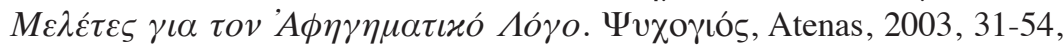
199-200.

GoufAS, K., The reception of Pope Joan in Greece 1866. University of Birmingham, 2004.

MarCo Hierro, E., "La papisa Juana de Enmanuel Roídis”. En Erytheia 23 (2002), 307-330.

Oronzo, G., Religiosidad popular en la alta Edad Media, Madrid, 1995.

ORTOLÁ SALAS, F.J.:"El griego a la sombra de un debate milenario: la cuestión de la lengua en Grecia. IV Congreso de Lingüística general, Cádiz 3 al 6 de abril de 2000.Cádiz 2003, vol. IV, 1973-1982.

Politis, I., Historia de la Literatura Griega moderna (Traducción al español de Goyita Núñez. Madrid, 1994).

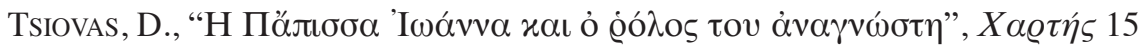
(1985), 427- 442.

\section{Traducciones de Emmanuil Roídis al español}

La papisa Juana. Un estudio sobre la Edad Media. 2006. Secretariado de Publicaciones de la Universidad de Sevilla. Traducción de Carmen Vilela. Premio Nacional de las Editoriales Universitarias españolas a la mejor traducción del año 2006. Premio Andaluz de Traducción 2007.

Paseos por Atenas. Ensayos y estudios históricos. 2008. Secretariado de Publicaciones de la Universidad de Sevilla. Edición, selección de artículos y traducción de Carmen Vilela.

Relatos de Siros. Recuerdos y reflexiones. 2010. Secretariado de Publicaciones de la Universidad de Sevilla. Edición, selección de relatos y traducción de Carmen Vilela. Premio Nacional de Traducción 2011, otorgado por el Ministerio de Cultura y Turismo de la República Helénica. 